Review

\title{
Regional Suppression of Bactrocera Fruit Flies (Diptera: Tephritidae) in the Pacific through Biological Control and Prospects for Future Introductions into Other Areas of the World
}

\author{
Roger I. Vargas ${ }^{1}{ }^{*}$, Luc Leblanc ${ }^{2}$, Ernest J. Harris ${ }^{1}$ and Nicholas C. Manoukis ${ }^{1}$ \\ 1 USDA-ARS, U.S. Pacific Basin Agricultural Research Center, 64 Nowelo St., Hilo, HI 96720, \\ USA; E-Mails: ernest96822@lycos.com (E.J.H.); nicholas.manoukis@ars.usda.gov (N.C.M.) \\ 2 Department of Plant Environmental Protection Sciences, University of Hawaii, Honolulu, \\ HI 96822, USA; E-Mail: leblanc1@ctahr.hawaii.edu
}

* Author to whom correspondence should be addressed; E-Mail: roger.vargas@ars.usda.gov; Tel.: +1-808-959-4329.

Received: 6 June 2012; in revised form: 18 July 2012 / Accepted: 26 July 2012 /

Published: 10 August 2012

\begin{abstract}
Bactrocera fruit fly species are economically important throughout the Pacific. The USDA, ARS U.S. Pacific Basin Agricultural Research Center has been a world leader in promoting biological control of Bactrocera spp. that includes classical, augmentative, conservation and IPM approaches. In Hawaii, establishment of Bactrocera cucurbitae (Coquillett) in 1895 resulted in the introduction of the most successful parasitoid, Psyttalia fletcheri (Silvestri); similarly, establishment of Bactrocera dorsalis (Hendel) in 1945 resulted in the introduction of 32 natural enemies of which Fopius arisanus (Sonan), Diachasmimorpha longicaudata (Ashmead) and Fopius vandenboschi (Fullaway) were most successful. Hawaii has also been a source of parasitoids for fruit fly control throughout the Pacific region including Australia, Pacific Island Nations, Central and South America, not only for Bactrocera spp. but also for Ceratitis and Anastrepha spp. Most recently, in 2002, F. arisanus was introduced into French Polynesia where B. dorsalis had invaded in 1996. Establishment of D. longicaudata into the new world has been important to augmentative biological control releases against Anastrepha spp. With the rapid expansion of airline travel and global trade there has been an alarming spread of Bactrocera spp. into new areas of the world (i.e., South America and Africa). Results of studies in Hawaii and French Polynesia, support parasitoid introductions into South America
\end{abstract}


and Africa, where B. carambolae and B. invadens, respectively, have become established. In addition, $P$. fletcheri is a candidate for biological control of $B$. cucurbitae in Africa. We review past and more recent successes against Bactrocera spp. and related tephritids, and outline simple rearing and release methods to facilitate this goal.

Keywords: parasitoids; Braconidae; Tephritidae; Bactrocera; Hawaii

\section{Introduction}

Fruit flies (Diptera: Tephritidae) are among the most economically important pests attacking soft fruits worldwide [1]. The Bactrocera genus is particularly important throughout the Pacific. It consists of at least 440 species distributed primarily in tropical Asia, Australia, and the South Pacific [1]. Bactrocera species are well-documented invaders and rank high on quarantine lists worldwide [2]. Polyphagy, superior mobility and dispersive powers, and high reproductive rates are among the common traits of invasive Bactrocera species. Throughout Pacific Island Nations, fruit flies have: (1) limited the development of a diversified tropical fruit and vegetable industry; (2) required that commercial fruits undergo quarantine treatment prior to export; and (3) provided a breeding reservoir for their introduction into other parts of the world due to unprecedented travel and trade between countries. Three invasive Bactrocera species (melon fly, Bactrocera. cucurbitae (Coquillett) (introduced in 1895) Figure 1b, oriental fruit fly, Bactocera dorsalis (Hendel) (1945) Figure 1a, and Malaysian fruit fly, Bactrocera latifrons (Hendel) (1983)), have been devastating to Hawaiian agriculture for over 100 years and have been studied extensively [3]. In addition to the development of area-wide technologies such as the sterile insect technique, protein bait sprays, and male annihilation, Hawaii has been a world leader in the development of classical, augmentative and conservation biological control approaches using parasitoid wasps (Hymenoptera: Braconidae) to suppress Bactrocera species.

Figure 1. (a) Bactrocera dorsalis; (b) Bactrocera cucurbitae.

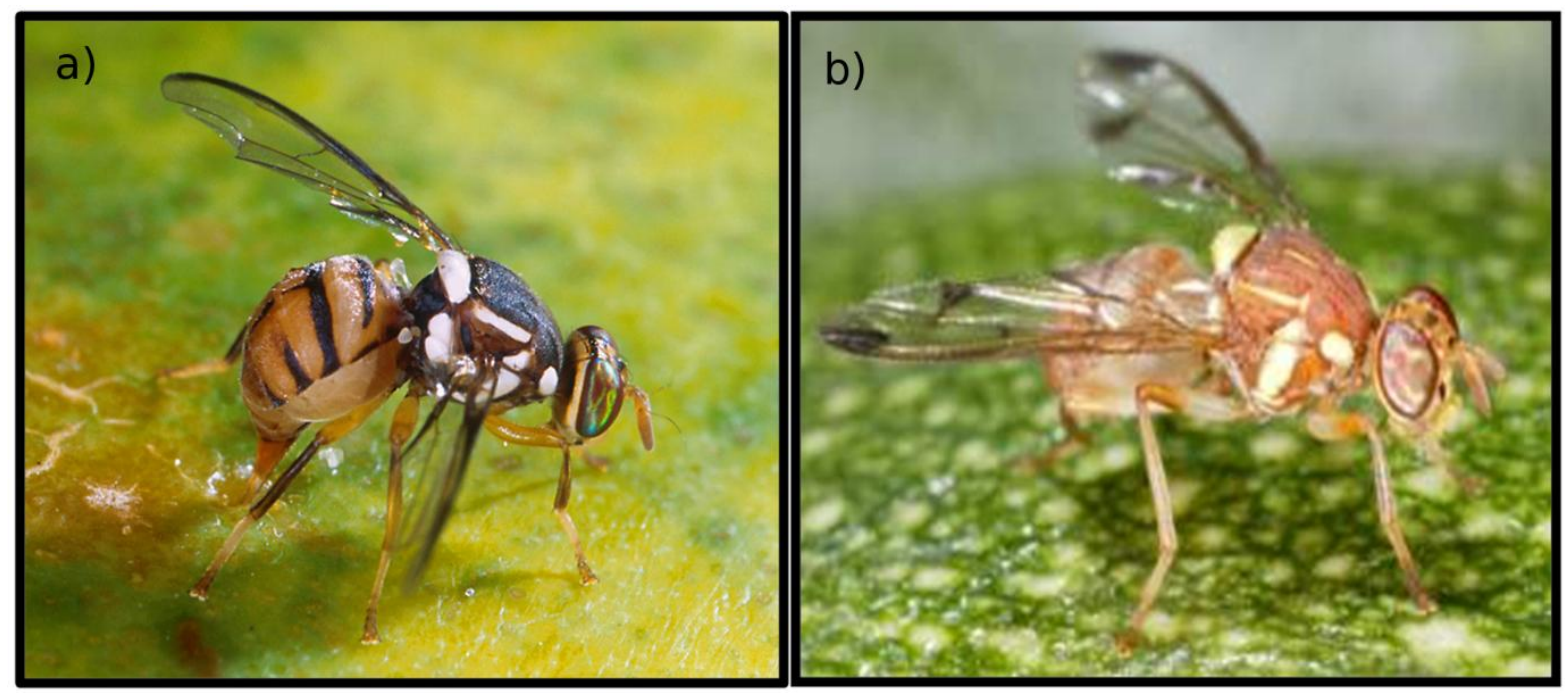


We anticipate that with the recent introductions of $B$. cucurbitae, B. latifrons, and Bactrocera invadens Drew, Tsuruta, and White into Africa and Bactrocera carambolae Drew and Hancock into South America [4,5], there will be increased interest in biological control. The objectives of this paper are to (1) review past and recent biological control work in Hawaii and French Polynesia, particularly with respect to the Bactrocera species; (2) summarize the various introductions throughout the region; (3) summarize successes and failures; (4) summarize rearing and release methods for future introductions; and (5) comment on prospects for future introductions into other parts of the world.

\section{Biological Control of Fruit Flies in Hawaii}

Introduction of invasive Bactrocera spp into Hawaii resulted in the initiation of extensive biological control programs. Initially these were classical biological control programs, but later, when mass rearing was perfected, augmentative releases were done. For example, establishment of $B$. cucurbitae in Hawaii in 1895 resulted in the introduction of eight species of hymenopterous parasitoids and six predators [6]. However, except for the parasitoid Psyttalia fletcheri (Silvestri), a widespread larval-pupal parasitoid of B. cucurbitae in India and introduced into Hawaii in 1916, the natural enemies were of little importance from the standpoint of biological control due to their scarcity and non-specificity to B. cucurbitae [7,8]. The host fruit species infested by B. cucurbitae appears to influence rate of parasitization by $P$. fletcheri. For example, Nishida [6] found little or no parasitization of larvae in papaya (Carica papaya L.), bell pepper (Capsicum annuum L.), or tomato (Lycopersicon esculentum Mill.), while Willard [7] reported that parasitization ranged from $7.3 \%$ to $29.8 \%$ in cucumber (Cucumis sativus L.) and was as high as $96.9 \%$ on wild bitter melon (Momordica charantia L.). Parasitization is also influenced by the location of host larvae within the plant. For example, in melons, where the larvae may be found in both vines and fruits, consistently higher parasitization was obtained in vines than in fruit [6]. Apparently, in vines, the larvae remain just beneath the epidermis throughout the developmental period, remaining within reach of the parasitoid's ovipositor. In contrast, larvae infesting fruit have a tendency to burrow deeply into the fruit flesh during later stages of development and consequently become less accessible to parasitoids. Interestingly, B. cucurbitae is generally immune to the development of Fopius arisanus (Sonan), a very successful braconid parasitoid of B. dorsalis [9]. However, Harris et al. [9] demonstrated that concurrent releases of F. arisanus and P. fletcheri increased suppression of $B$. cucurbitae in patches of wild ivy gourd (Coccinia grandis L.) compared to releases of $P$. fletcheri alone. It is suspected that, although survival of F. arisanus in B. cucurbitae is low, mortality due to puncturing of eggs added to suppression. Nonetheless, $P$. fletcheri has remained the most important parasitoid of B. cucurbitae for almost a century [10].

With the introduction of $B$. dorsalis into Hawaii in 1945, the largest classical biological control program against fruit flies to date was undertaken to reduce its serious damage to fruits [8]. Thirty-two natural enemies were released between 1947 and 1952 [11]. Diachasmimorpha longicaudata (Ashmead) increased rapidly following its release in 1948, but suddenly lost its dominant position during the latter half of 1949 to Fopius vandenboschi (Fullaway), which was later superseded by the egg-pupal parasitoid $F$. arisanus [12-14]. Since its establishment, $F$. arisanus has resulted in a dramatic reduction in fruit infestation in Hawaii through a high level of B. dorsalis parasitism $(65 \%-70 \%)$, and has remained the 
dominant parasitoid species $[15,16]$. Clearly, given the success of fruit fly biological control in Hawaii, a wealth of information was generated that can apply to other areas throughout the Pacific and the world.

Although no parasitoids were deliberately introduced to control B. latifrons, the third economically important Bactrocera species detected in Hawaii in 1983, five primary parasitoid species have been recovered from individually held B. latifrons puparia: F. arisanus, Psyttalia incisi (Silvestri), D. longicaudata, Diachasmimorpha tryoni (Cameron) and Tetrastichus giffardianus Silvestri [17]. Of these, F. arisanus was the predominant species recovered at study sites [17].

\section{Biological Control Programs for Fruit Flies in French Polynesia}

The invasion of $B$. dorsalis (1996) was the most devastating of four accidental introductions of economically important Bactrocera species into French Polynesia, the others being Bactrocera kirki (Froggatt) (1928), Bactrocera tryoni (Froggatt), Queensland fruit fly, (1970), and Bactrocera xanthodes (Broun), Pacific fruit fly, (1998) [18]. Bactrocera dorsalis has been reported in the Society, Austral and Marquesas Islands while B. xanthodes is confined to the Austral Islands. Studies in French Polynesia are unique in that emergence data from large numbers of fruit samples were compared before and after releases of $F$. arisanus on Tahiti Island over ca. a 10 year period [19,20]. Starting in 2002, 10 parasitoid shipments from Hawaii, over 500,000 insects, were dispersed in two major locations and 10 minor locations around Tahiti Island. Fopius arisanus was established throughout all 21 communities within 3 years on Tahiti Island and nearby Moorea Island [19]. It became so abundant in guava fruits that parasitoids recovered from wild fruits were used to establish it on the Society Islands of Huahine, Tahaa, and Raiatea where B. dorsalis had spread [19]. By 2009 mean ( \pm SD) parasitism of fruit flies infesting P. guajava, Inocarpus fagifer (Parkinson) Fosberg (Polynesian chestnut) and Terminalia catappa. (tropical almond) fruits on Tahiti Island was $64.8 \pm 2.0 \%$ [20]. A second parasitoid, D. longicaudata, was released in 2007 [20]. Five shipments of D. longicaudata (of approximately 5,000 each with a total of about 10,000 surviving wasps) were made between September 2007 and August 2008. Although also becoming widespread, parasitism rates of $D$. longicaudata have not been higher than $10 \%$ [20]. As a result of parasitoid introduction, numbers of B. dorsalis, B. tryoni and B. kirki emerging (per $\mathrm{kg}$ of fruit) declined sharply. For example, for $P$. guajava there was a decline, between 2003 and 2009, of 92.3, 96.8, and 99.6\% for each of the fly species, respectively [19]. Analysis of co-infestation patterns (1998-2009) of B. dorsalis, B. tryoni, and B. kirki in four main host fruits suggest that $B$. dorsalis has become the most abundant species wherever it occurs [20]. Establishment of $F$. arisanus in French Polynesia is the most successful example of classical biological control of fruit flies in the Pacific outside of Hawaii and it was secondarily introduced from Tahiti as B. dorsalis spread to other French Polynesian islands, most recently to the Marquesas Islands (Nuku Hiva, Hiva Oa and Fatu Hiva) [20].

French Polynesia is comprised of over 118 islands and atolls scattered over approximately 2,500,000 $\mathrm{km}^{2}$ of ocean. Bactrocera dorsalis is currently established in the Society, Marquesas and Austral Islands of French Polynesia. Initially it was envisioned that $F$. arisanus could be mass reared in Hawaii at an estimated cost of US \$2,000 per 1,000,000 parasitoids [21], and transferred to other islands as $B$. dorsalis was progressively spreading throughout French Polynesia. However, when $F$. arisanus became numerous in fruits infested with $B$. dorsalis on Tahiti Island, it became more cost 
effective to recover wasps from field-collected fruits and ship them to the outer islands, than to mass rear them in the laboratory. This is now the preferred approach for shipments and quick establishment to new islands where $B$. dorsalis has spread [19].

\section{Hawaii as a Source of Parasitoids throughout the Pacific}

From 1935 to 2008 Hawaii has been very active in exporting fruit fly parasitoids throughout the world for suppression of a variety of fruit fly species with varying degrees of success [20,22]. Originally established in Hawaii around 1948, F. arisanus has since been released in 11 Pacific Island countries against various Bactrocera spp Figure 2a. Establishment has been confirmed in seven countries (Table 1). Similarly, D. longicaudata, also introduced into Hawaii in 1948, has been released in six countries with establishment confirmed in three countries (Figure 2b, Table 1). Throughout the Pacific region parasitism rates have varied depending on parasitoid species (F. arisanus or D. longicaudata), target host fruit fly species, and host fruit (Table 1). The highest $F$. arisanus parasitism rates have been obtained with the B. dorsalis complex species in Hawaii, French Polynesia, and Palau. Psyttalia fletcheri was established in Hawaii in 1916 and has been released and established in the Northern Mariana Islands (starting in 1950) and the Solomon Islands (in 1997) [23].

The extensive biological control programs in Hawaii have also resulted in shipments of parasitoids to various localities in the US and Latin America [22], with the largest programs in Mexico, Costa Rica and Florida. The program in Costa Rica was in direct response to the establishment of Ceratitis capitata (Wiedemann), Mediterranean fruit fly, and its subsequent expansion to the rest of Central America [22]. Costa Rica then became the source of parasitoid introductions to 11 other American countries. Most of the control efforts targeted C. capitata and Anastrepha spp. in Central America (Nicaragua, Panama, El Salvador, Guatemala and Trinidad) and C. capitata and Anastrepha fraterculus (Wiedemann), South American fruit fly, in South America (Argentina, Bolivia, Peru, and Venezuela) [22]. The two most successful introduced parasitoids were D. longicaudata and the eulophid Aceratoneuromyia indica (Silvestri), both larval parasitoids [22]. These have become established on A. fraterculus, Anastrepha ludens (Loew) (Mexican fruit fly), Anastrepha obliqua (Macquart) (West Indian fruit fly), Anastrepha serpentina (Wiedemann) (sapote fruit fly), and Anastrepha striata Schiner (guava fruit fly) [22]. In Florida, populations of Anastrepha suspensa (Loew) (Caribbean fruit fly) decreased by $40 \%$ in the years following releases of the parasitoids Doryctobracon areolatus (Szepligeti) and D. longicaudata [24]. 
Figure 2. Introductions of parasitoids (Braconidae) for fruit fly biological control in the Pacific. (a) Fopius arisanus; (b) Diachasmimorpha longicaudata.

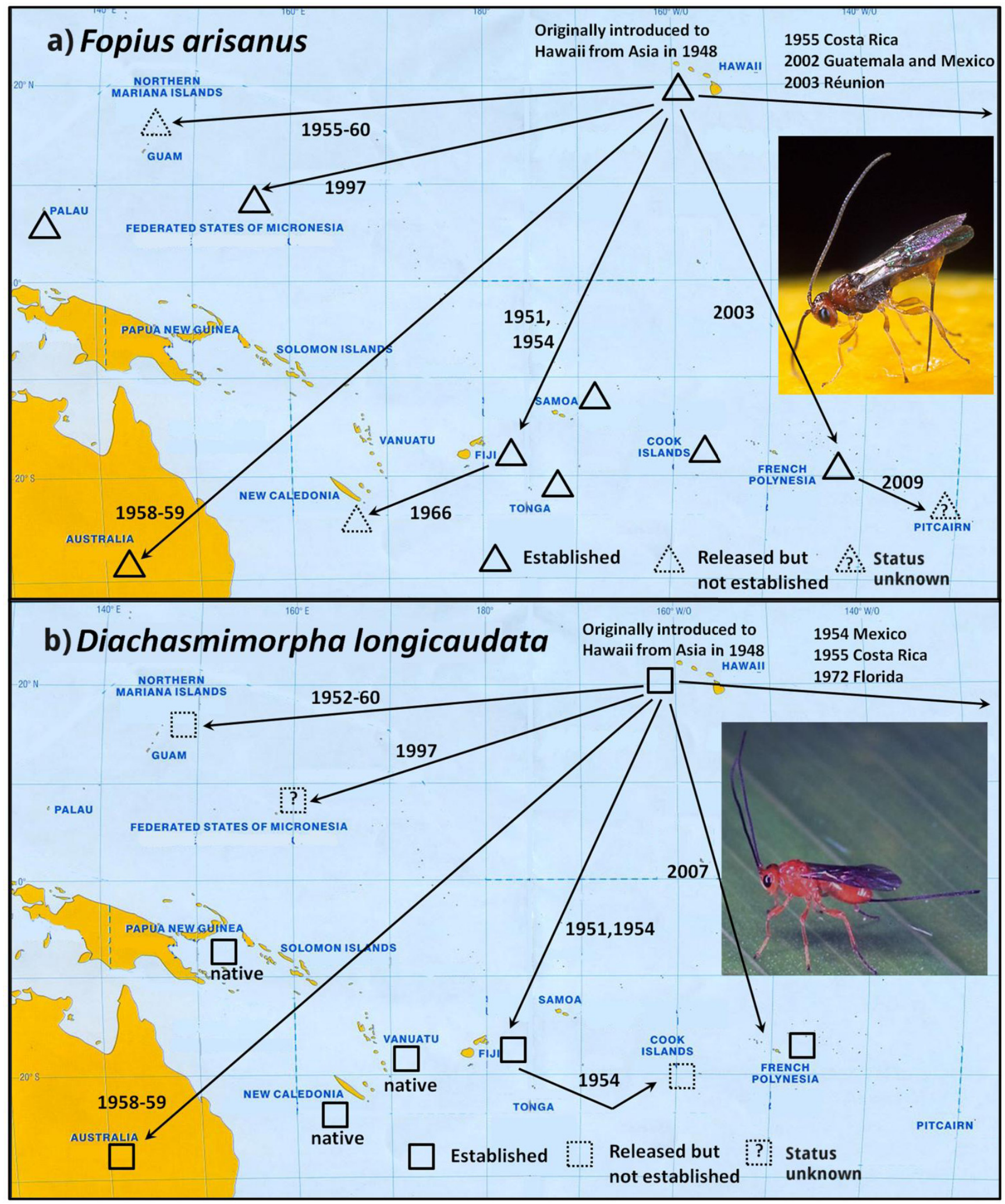


Table 1. Percent parasitism by $F$. arisanus and D. longicaudata in various countries where they have been introduced.

\begin{tabular}{|c|c|c|c|c|c|c|c|c|c|c|c|c|c|}
\hline Country & Parasitoids & Target economic species & $\begin{array}{c}\text { Assessment } \\
\text { period }\end{array}$ & 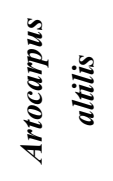 & 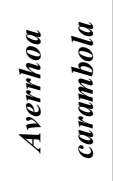 & 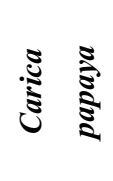 & $\begin{array}{c}7 \\
\overline{2} \\
0 \\
0 \\
0 \\
0\end{array}$ & 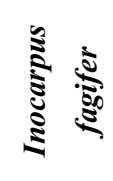 & 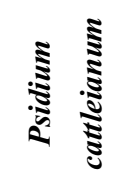 & 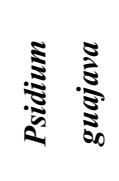 & $\begin{array}{l}\text { जे } \\
\text { जे } \\
\text { जे }\end{array}$ & 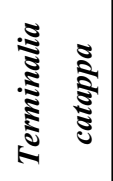 & Reference $^{2}$ \\
\hline Australia $^{3}$ & F. arisanus & B. tryoni & $1960-64$ & --- & $0-78 \%$ & --- & $0-21 \%$ & --- & $0-2 \%$ & $0-21 \%$ & --- & --- & {$[25,26]$} \\
\hline Australia $^{4}$ & D. longicaudata & B. tryoni & $1963-65$ & --- & --- & --- & --- & --- & $1 \%-5 \%$ & $0-7 \%$ & --- & --- & {$[26]$} \\
\hline Cook Islands & F. arisanus & B. melanotus, B. xanthodes & $1991-92$ & $0.6 \%$ & --- & $4.6 \%$ & -- & $1.0 \%$ & -- & $11.5 \%$ & $5.4 \%$ & $10.6 \%$ & RFFP \\
\hline Fiji Islands & F. arisanus & B. passiflorae, B. xanthodes & $1959-63$ & -- & -- & --- & $21.4 \%$ & $0.5 \%$ & $54.8 \%$ & $22.1 \%$ & --- & --- & {$[27,28]$} \\
\hline Fiji Islands & D. longicaudata & B. passiflorae, B. xanthodes & $1959-63$ & --- & --- & --- & $0.3 \%$ & $8.0 \%$ & $6.5 \%$ & $2.1 \%$ & --- & --- & {$[27,28]$} \\
\hline Fiji Islands & F. arisanus & B. passiflorae, B. xanthodes & 1990-99 & $3.3 \%$ & --- & -- & $23.3 \%$ & $30.3 \%$ & -- & $23.8 \%$ & $6.2 \%$ & $2.3 \%$ & RFFP \\
\hline French Polynesia $^{5}$ & F. arisanus & B. dorsalis & 2005-09 & $34.7 \%$ & $38.5 \%$ & $32.4 \%$ & $25.9 \%$ & $50.2 \%$ & $53.4 \%$ & $54.2 \%$ & $58.7 \%$ & $45.5 \%$ & RFFP \\
\hline French Polynesia $^{5}$ & D. longicaudata & B. dorsalis & 2008-09 & $3.5 \%$ & $0.0 \%$ & $0.8 \%$ & $1.3 \%$ & $2.4 \%$ & $8.8 \%$ & $0.6 \%$ & --- & $2.2 \%$ & {$[20]$} \\
\hline Hawaii (Kauai) & F. arisanus & B. dorsalis & $1988-89$ & -- & --- & -- & $35.2 \%$ & -- & $59.8 \%$ & $58.6 \%$ & $50.4 \%$ & --- & {$[16]$} \\
\hline Hawaii (Kauai) & D. longicaudata & B. dorsalis & $1988-89$ & --- & --- & --- & $0.3 \%$ & --- & $2.6 \%$ & $0.2 \%$ & $0.8 \%$ & --- & {$[16]$} \\
\hline Palau & F. arisanus & $\begin{array}{l}\text { B. philippinensis, } \\
\text { B. frauenfeldi } \\
\end{array}$ & 2001 & --- & $22.2 \%$ & --- & --- & --- & --- & $4.5 \%$ & $11.7 \%$ & --- & RFFP \\
\hline Samoa & F. arisanus & B. kirki, B. xanthodes & $1991-95$ & --- & --- & $0.8 \%$ & --- & --- & --- & $6.8 \%$ & --- & $0.4 \%$ & RFFP \\
\hline Tonga & F. arisanus & $\begin{array}{c}\text { B. facialis, B. kirki, } \\
\text { B. xanthodes }\end{array}$ & $1991-95$ & $0.7 \%$ & --- & --- & --- & $0.1 \%$ & --- & $1.4 \%$ & $1.2 \%$ & $1.8 \%$ & RFFP \\
\hline
\end{tabular}

${ }^{1}$ C. paradisi, C. reticulata and C. sinensis in Australia; C. latifolia, C. maxima and C. sinensis in French Polynesia; C. maxima and C. sinensis in Fiji, and C. sinensis in Hawaii; ${ }^{2}$ Regional Fruit Fly Project (RFFP): Intensive host surveys carried out under the Regional Fruit Fly Projects in the Pacific; ${ }^{3}$ Northern Queensland (Cairns area); ${ }^{4}$ Lord Howe Island; ${ }^{5}$ Tahiti Island. 


\section{Rearing and Release Protocol}

We focus here on $F$. arisanus as a useful example of procedures for rearing fruit fly parasitoids, because it has historically been considered difficult to rear and maintain under colony conditions [13,14,22,29-31]. Complications with establishing and maintaining $F$. arisanus in the insectary might arise from the fact that it is an ovo-parasitoid, one of only three known species of opiine parasitoids to infest the host during that stage [32]. Despite these difficulties, United States Department of Agriculture-Agricultural Research Service (USDA-ARS) researchers were able to develop a robust protocol for establishing and maintaining F. arisanus in colony [33-35]. This basic protocol was recently described in a video-article [36], in an effort to facilitate the adaption of these methods in other parts of the world. We provide an overview here of the rearing method; interested readers are referred to the sources above for further details.

The current protocol used at USDA-ARS in Hilo, HI involves three major components: (1) maintaining a stock of host fruit flies (B. dorsalis is mainly used for this purpose, although $F$. arisanus is known to parasitize other species); (2) parasitization of the host eggs, development of the parasitoid in the host and enrichment of the proportion of parasitoids; and (3) maintenance of the parasitoid colony under conditions that allow high survivorship, sexual maturation and insemination of females. These three components are shown schematically in the flow chart in Figure 3. The first component, maintaining host fruit fly stocks, has been extensively covered by Vargas [37] and will not be discussed here.

Figure 3. Rearing protocol for Fopius arisanus and related parasitoids.

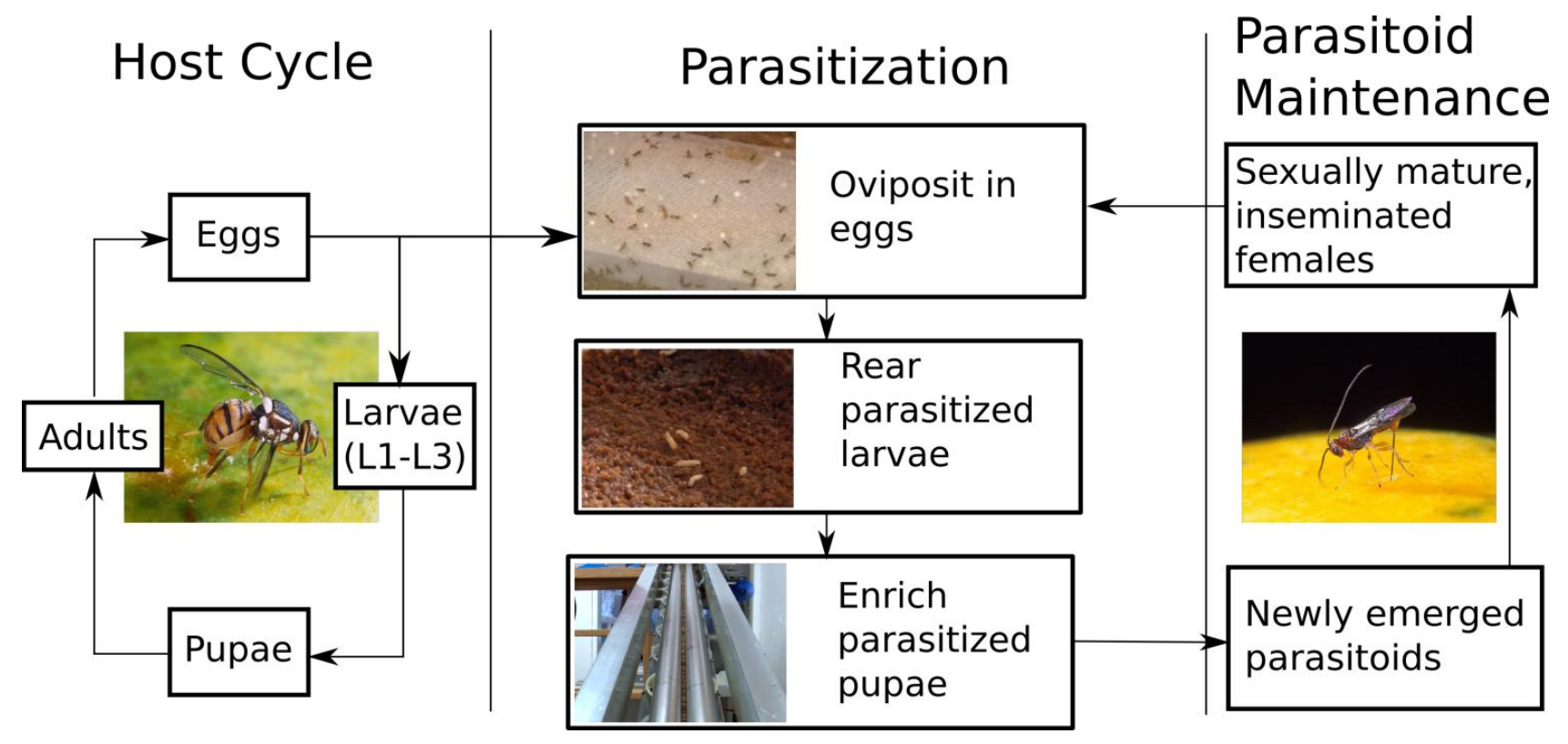

Rearing of $F$. arisanus has been covered in detail by Bautista et al. [35] and most recently in a video by Manoukis et al. [36] and will only be summarized here. The second component, "Parasitization", is the most technically involved and specific to $F$. arisanus. Fruit fly eggs are placed on an agar or glycerin substrate that has been prepared in a shallow dish. These dishes are then placed under the screened bottom of small holding cages containing mature $F$. arisanus. Females are then given $21 \mathrm{~h}$ to parasitize the eggs. The substrate with eggs is then placed on a dish of larval diet within a large covered 
fiberglass pupation container, and kept in the dark at $27{ }^{\circ} \mathrm{C}$ and $80 \% \mathrm{RH}$ for one week. Pupae are then sifted from vermiculite or sand at the bottom of the fiberglass container and sorted by size. Pupae that are between 0.165 and $0.226 \mathrm{~cm}$ in diameter contain mostly parasitoids [35]; these are the pupae that are held for emergence after 7 more days.

For the third component, Parasitiod Maintenance, there are a few important practices worthy of mention. Fopius arisanus should be kept in small cages (approximately $25 \mathrm{~cm}^{3}$ ). These should have a removable glass front, screened sides, top and bottom, and an access port in the back. The glass front should be tinted along the bottom edge (approx. $6 \mathrm{~cm}$ ) to prevent parasitoids from accumulating in the corners and crowding each other. Parasitized pupae should be placed in a container with a coarse screened lid that allows $F$. arisanus to pass through while trapping any remaining fruit flies.

Fopius arisanus cultures are held in a room maintained at $24{ }^{\circ} \mathrm{C}$ and $45 \% \mathrm{RH}$ with a $12: 12$ photoperiod and good ventilation. Feeding is accomplished by streaking spun honey along the top of the holding cages at least three times per week. Agar blocks are also placed on top of the holding cages to provide moisture for the parasitoids.

As an alternative to small cubical cages, a cylindrical cage (Figure 4) was also developed for the dual purpose of rearing (Figure 4a) and transport and release (Figure 4b) of the parasitoids [9]. The $60 \times 65 \mathrm{~cm}$ screened cage can hold 10,000 adult $F$. arisanus. Some larger "release-only" cages used in the Hawaii Area-Wide Pest Management (AWPM) program, hold up to 30,000 parasitoids [38]. The cage shown in the figure includes a water dispenser and a vertical stinging unit (Figure 4c), and food is provided as spun honey smeared on the outside walls of the cage [9]. To initiate a colony, parasitized pupae are placed in a tray in a trapdoor below the cage (Figure 4d) [9]. Emerging parasitoids escape through the screened cage floor, while flies are excluded because of small screen mesh size $\left(0.1 \mathrm{~cm}^{2}\right)$ [35]. Bactrocera dorsalis eggs as host material are provided on a stinging unit (Figure 4e) that consists of agar poured over a rigid screen mesh, covered with tissue paper, over which eggs are evenly distributed using a fine paintbrush, and covered with a fine fabric screen to hold eggs in place [35]. The prepared unit (Figure 4f) is inserted through a slot on the cage roof (Figure $4 \mathrm{~g}$ ), allowing wasps to sting the fly eggs held in the vertical unit (Figure 4h) [35]. After $24 \mathrm{~h}$ of exposure, the unit is removed and the agar plate with parasitized eggs is placed over larval diet [35].

Figure 4. (a to $\mathbf{h}$ ) The cylindrical cage for mass-rearing and release of Fopius arisanus.

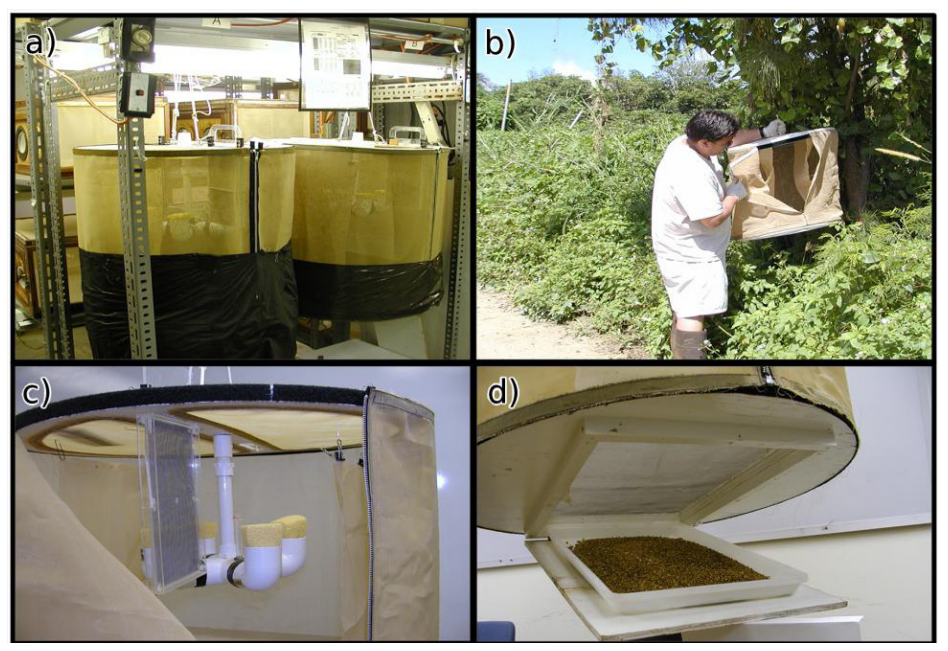


Figure 4. Cont.

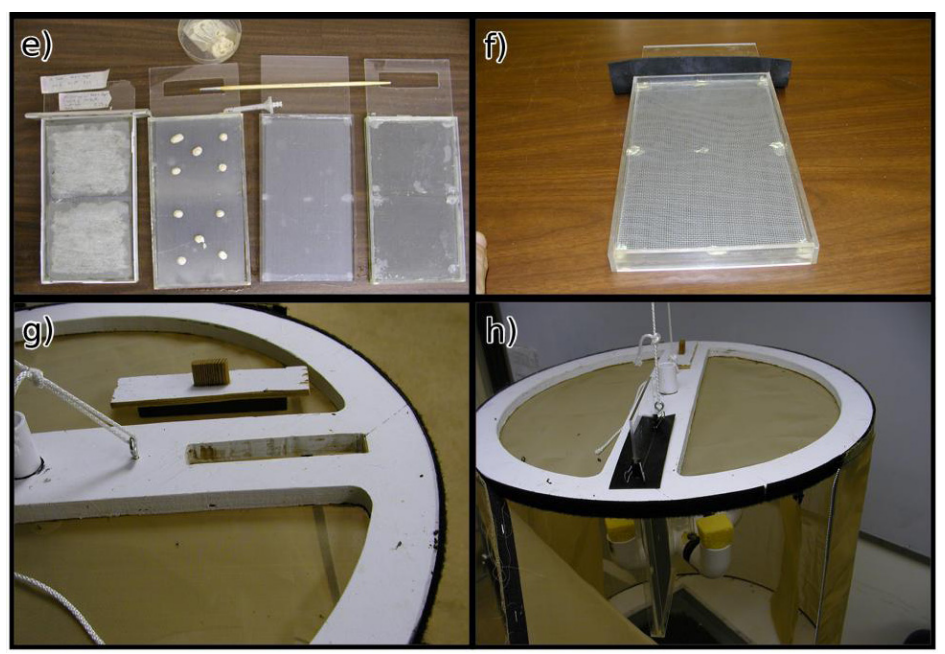

\section{Prospects for the Future}

Fopius arisanus occurs from south India to Taiwan, and has been introduced and established in Australia, Cook Islands, Costa Rica, Fiji, Hawaii, Mauritius, Samoa, Tonga, Reunion, and Israel [39,40]. Diachasmimorpha longicaudata occurs throughout southeast Asia, east to Papua New Guinea, and has been introduced and established in Australia, Fiji, Mexico, Costa Rica, Florida and Trinidad on a variety of hosts [40], and was more recently recorded from Vanuatu [39]. Psyttalia fletcheri is a widespread larval-pupal parasitoid of B. cucurbitae and occurs throughout India, Sri Lanka, Malaysia and Indonesia, and has been established in Hawaii, the Solomon Islands and Northern Marianas [40]. Perhaps no fruit fly parasitoids have been studied more thoroughly than F. arisanus, D. longicaudata and Psyttalia concolor (Szépligeti). Because of its habit of attacking host eggs, which are more exposed below the fruit skin surface than larvae, $F$. arisanus can achieve high levels of parasitism, often surpassing $50 \%$ in the field [16,41]. In Hawaii, its introduction resulted in a 95\% reduction in the B. dorsalis population, compared to the 1947-1949 peak abundance of B. dorsalis [42]. Furthermore, F. arisanus also became the major parasitoid of C. capitata in Hawaii [42,43]. Haramoto and Bess [15] reported that the mean number of fruit fly pupae (B. dorsalis and C. capitata) collected from Coffea arabica L. (coffee) berries in Kona, Hawaii, decreased from 23.6 pupae per 100 fruits (8.7\% parasitism) in 1949 to 5.2 (66.6\% parasitism) in 1969. With this level of impact on infestation level, establishment of $F$. arisanus has reduced the threat of movement of fruit flies to the mainland from Hawaii. When D. longicaudata was established in French Polynesia to complement $F$. arisanus, data suggested it rarely accounted for more than $8.8 \%$ parasitism, but still has become widespread [20]. Nonetheless, establishment of D. longicaudata has increased total parasitoid mortality and more time may be necessary for D. longicaudata populations to increase [20]. During surveys, one specimen of Diachasmimorpha tryoni (Cameron) was reared from Inocarpus fagifer (Polynesian chestnut) on Tahiti in October 2003, probably a result of previous releases against B. kirki previously not known to have established [44]. In Florida, populations of $A$. suspensa decreased by $40 \%$ in the years following releases of the parasitoids Doryctobracon areolatus (Szépligeti) and D. longicaudata [24]. The larval parasitoid, Psyttalia cf. concolor, collected from tephritids infesting coffee in Kenya and reared on C. capitata by USDA-Animal Plant Health Inspection Service, Plant Protection and Quarantine in Guatemala, was recently imported into California for biological control 
of olive fruit fly, Bactrocera oleae (Gmelin) (introduced in 1998). Further details are found in Yokoyama et al. [45].

Fopius arisanus polyphagy has been studied extensively [46]. For example, in Hawaii, it attacks eggs of B. dorsalis, C. capitata, and B. cucurbitae, but does not develop successfully in B. cucurbitae $[13,47]$. Sometimes $F$. arisanus adults emerge from field-collected fruits infested by several fruit fly species, so exact host relationships cannot be inferred accurately, unless the fruit fly species can be distinguished at the pupal stage [25]. Vargas et al. [43] segregated B. dorsalis and C. capitata pupae from field collections and found $F$. arisanus to also be the dominant $C$. capitata parasitoid in Hawaii. In Australia, Quimio and Walter [46] were able to rear $F$. arisanus on B. tryoni in the laboratory and it has also been recovered from the field [25], but percent parasitism is lower than on B. dorsalis (Table 1). Although B. tryoni parasitism in French Polynesia was never confirmed due to mixed infestation, $F$. arisanus was reared in the laboratory on B. tryoni [38]. It is suspected, as was the case in Hawaii with C. capitata, that $F$. arisanus also has an impact on lesser preferred species, such as $B$. tryoni, by increasing its numbers on a large $B$. dorsalis population. Furthermore, parasitism of B. tryoni and B. kirki eggs in fruits with mixed infestations may result in significant mortality of host species in the egg or larval stage, although parasitoids may have lower survivorship, as has been shown with B. cucurbitae [9,48].

\section{Conclusions}

In surveys in Hawaii, the egg-pupal parasitoid $F$. arisanus and the larval-pupal parasitoid D. longicaudata constitute $87.5 \%-95.1 \%$ and $0.9 \%-9 \%$ of the parasitoid guild, respectively, and are very common in tree fruits, particularly P. guajava and P. cattleianum (Sabine), strawberry guava [16]. Since its establishment in Hawaii, $F$. arisanus has resulted in a dramatic reduction in infestation of fruit through a high level of $B$. dorsalis parasitism (65\%-70\%) [15]. In Tahiti, parasitism on $P$. guajava, I. fagifer, and T. catappa fruit collections has increased from approximately $50 \%$ to $65 \%$ from 2006 to 2009 [20]. These percentages are very similar to those obtained in Hawaii and the observed increases during the period of $D$. longicaudata establishment would suggest few negative effects of D. longicaudata on $F$. arisanus [20].

The impact of $F$. arisanus releases has not always been as impressive in locations outside of Hawaii and French Polynesia to date [4]. For example, it was released and recovered in Costa Rica, but its impact has not been high, although little information is available on its present status or distribution on coffee farms, where C. capitata infests fruits [49]. Similarly, in Australia, F. arisanus was introduced from Hawaii and was established on the native B. tryoni in 1962, but reputedly had only a negligible effect [46]. Likewise, parasitism has been lower on the species of Bactrocera endemic to south Pacific Islands (Table 1) than on the B. dorsalis complex species.

The role of parasitoids were tested in the Hawaii AWPM fruit fly program at three levels of application: (1) conservation; (2) augmentative releases; and (3) classical releases [3]. Fopius arisanus and P. fletcheri were reared and released in wild guava and cucurbit patches, respectively, near agro-ecosystems [3], with the objective of demonstrating a cost-effective, sustainable technology that could be integrated with reduced risk bait sprays (i.e., GF-120 Fruit Fly Bait) and male annihilation treatments [Specialized Pheromone Lure Application Technology-Male Annihilation Technique (SPLAT-MAT)-Methyl Eugenol-Spinosad]. In augmentative releases of $P$. fletcheri against melon fly, numbers of $B$. cucurbitae 
emerging from fruits placed inside field treatment cages were reduced by up to 21 fold and numbers of parasitoids were increased by 11 fold [10]. In open field releases of $P$. fletcheri into ivy gourd patches throughout the Kailua-Kona area, parasitism rates were 4.7 times higher in release plots compared to those in control plots. However there was no significant reduction in emergence of flies from fruits. Similarly, in releases of $P$. fletcheri in zucchini plots in Waimea, there was an increase in parasitoid recovery rates, but no reduction in melon fly damage. Fopius arisanus was also tested as an augmentative tool in small plots of guava in Waimea where the existing population of F. arisanus was low. Levels of parasitism were increased, but infestation was not reduced [3]. Therefore although augmentative releases of parasitoids were shown to increase parasitism in the field, limited rearing capacity, the high cost and the limited impact at reducing fruit fly infestations below economic thresholds limited their level of implementation in a sustainable AWPM-program. On the other hand, classical biological control was demonstrated to be very cost effective and sustainable in the French Polynesia program.

The establishment of natural enemies of invasive tephritid fly pests may have significant and beneficial impacts in regions otherwise lacking in natural enemies. Results from Hawaii support introduction of $F$. arisanus and D. longicaudata into South America and Africa, where B. carambolae and B. invadens have become established, respectively [4,5]. It is also thought that $F$. arisanus and D. longicaudata evolved in areas where the $B$. dorsalis complex species are indigenous and their success is likely to be higher on species of that complex than other fruit flies. Given $F$. arisanus attacks the egg stage and forages on ripening fruits, while $D$. longicaudata attacks third instar larvae and tends to forage among fallen fruits [38], they are, to an extent, complementary to each other. Furthermore, based on data collected in Hawaii, F. arisanus and D. longicaudata could also be released against $B$. latifrons, which has recently invaded the African continent, and the peach fruit fly, B. zonata (Saunders), in Africa and the Indian Ocean region (e.g., [50]). Pysttalia fletcheri is also a candidate for releases in Africa where B. cucurbitae has invaded.

\section{Acknowledgments}

We are grateful to Neil Miller and Steven Souder, USDA, ARS, PBARC, Hilo, HI for their assistance with this research and manuscript. We also appreciate the technical assistance in French Polynesia of Rudolph Putoa, Axelle Maitere, Berthe Neagle, Djeeen Cheou, Jules Wohler, and Jean-Marc Tinirau, Service du Développement Rural, Département de la Protection des Végétaux, Papeete, Tahiti. Special thanks to Danny Seo, Michael McKenney, Thomas Mangine and Keith Shigeteni for their work in the insectary, essential to this work. We thank Ronald Mau, John Stark and Victoria Yokoyama for reviewing an earlier draft of this manuscript and Colin Mathis for help with the images. Finally, without USDA, Foreign Agricultural Service and USDA, ARS, Area-Wide Pest Management funds, this work could not have been accomplished.

This article reports the results of research only. Mention of proprietary product does not constitute an endorsement or recommendation by the USDA. 


\section{References}

1. White, I.M.; Elson-Harris, M.M. Fruit Flies of Economic Significance: Their Identification and Bionomics; CABI: Wallingford, UK, 1992.

2. Clarke, A.R.; Armstrong, K.F.; Carmichael, A.E.; Milne, J.R.; Raghu, S.; Roderick, G.K.; Yeates, D.K. Invasive phytophagous pests arising through a recent tropical evolutionary radiation: The Bactrocera dorsalis complex of fruit flies. Annu. Rev. Entomol. 2005, 50, 293-319.

3. Vargas, R.I.; Mau, R.F.L.; Jang, E.B.; Faust, R.M.; Wong, L.; Koul, O.; Cuperus, G.; Elliott, N. The Hawaii fruit fly areawide pest management programme. In Areawide Pest Management: Theory and Implementation; CABI: Cambridge, MA, USA, 2008; pp. 300-325.

4. Rousse, P.; Harris, E.J.; Quilici, S. Fopius arisanus, an egg-pupal parasitoid of Tephritidae. Overview. Biocontrol News Infor. 2005, 26, 59N-69N.

5. Drew, R.; Tsuruta, K.; White, I. A new species of pest fruit fly (Diptera: Tephritidae: Dacinae) from Sri Lanka and Africa. Afr. Entomol. 2005, 13, 149-154.

6. Nishida, T. Natural enemies of the melon fly, Dacus curcurbitae Coq. in Hawaii. Ann. Entomol. Soc. Am. 1955, 48, 171-178.

7. Willard, H.F. Opius fletcheri as a parasite of the melon fly in Hawaii. J. Agr. Res. 1920, 20, 423-438.

8. Clausen, C.P.; Clancy, D.W.; Chock, Q.C. Biological Control of the Oriental Fruit Fly (Dacus dorsalis Hendel) and Other Fruit Flies in Hawaii; Agricultural Research Service. US Dept. of Agriculture: Washington, DC, USA, 1965.

9. Harris, E.J.; Bautista, R.C.; Vargas, R.I.; Jang, E.B.; Eitam, A.; Leblanc, L. Suppression of melon fly (Diptera: Tephritidae) populations with releases of Fopius arisanus and Psyttalia fletcheri (Hymenoptera: Braconidae) in North Shore Oahu, HI, USA. Biocontrol 2010, 55, 593-599.

10. Vargas, R.I.; Long, J.; Miller, N.W.; Delate, K.; Jackson, C.G.; Uchida, G.K.; Bautista, R.C.; Harris, E.J. Releases of Psyttalia fletcheri (Hymenoptera: Braconidae) and sterile flies to suppress melon fly (Diptera: Tephritidae) in Hawaii. J. Econ. Entomol. 2004, 97, 1531-1539.

11. Bess, H.A.; van Den Bosch, R.; Haramoto, F.H. Fruit fly parasites and their activities in Hawaii. P. Hawaii Entomol. Soc. 1961, 17, 367-378.

12. van den Bosch, R.; Haramoto, F.H. Competition among parasites of the Oriental fruit fly. P. Hawaii Entomol. Soc. 1953, 15, 201-206.

13. Haramoto, F.H. The Biology of Opius oophilus Fullaway (Hymenoptera: Braconidae). M.S. thesis, University of Hawaii, Honolulu, HI, USA, June 1953.

14. Ramadan, M.M.; Wong, T.T.Y.; Beardsley, J.W. Reproductive behavior of Biosteres arisanus (Sonan) (Hymenoptera: Braconidae), an egg-larval parasitoid of the Oriental fruit fly. Biol. Control 1992, 2, 28-34.

15. Haramoto, F.H.; Bess, H.A. Recent studies on the abundance of the Oriental and Mediterranean fruit flies and the status of their parasites. Proc. Hawaii. Entomol. Soc. 1970, 20, 551-566.

16. Vargas, R.I.; Stark, J.D.; Uchida, G.; Purcell, M. Opiine parasitoids (Hymenoptera, Braconidae) of Oriental fruit fly (Diptera, Tephritidae) on Kauai Island, Hawaii-Islandwide relative abundance and parasitism rates in wild and orchard guava habitats. Environ. Entomol. 1993, 22, $246-253$. 
17. Bokonon-Ganta, A.H.; Ramadan, M.M.; Messing, R.H. Reproductive biology of Fopius ceratitivorus (Hymenoptera: Braconidae), an egg-larval parasitold of the Mediterranean fruit fly, Ceratitis capitata (Diptera: Tephritidae). Biol. Control 2007, 41, 361-367.

18. Leblanc, L.; Putoa, R. Fruit Flies in French Polynesia and Pitcairn Islands; Plant Protection Service, Secretariat of the Pacific Community: Suva, Fiji, 2000; p. 4.

19. Vargas, R.I.; Leblanc, L.; Putoa, R.; Eitam, A. Impact of introduction of Bactrocera dorsalis (Diptera:Tephritidae) and classical biological control releases of Fopius arisanus (Hymenoptera:Braconidae) on economically important fruit flies in French Polynesia. J. Econ. Entomol. 2007, 100, 670-679.

20. Vargas, R.I.; Leblanc, L.; Putoa, R.; Piñero, J.C. Population dynamics of three Bactrocera spp. fruit flies (Diptera: Tephritidae) and two introduced natural enemies, Fopius arisanus (Sonan) and Diachasmimorpha longicaudata (Ashmead) (Hymenoptera: Braconidae), after an invasion by Bactrocera dorsalis (Hendel) in Tahiti. Biol. Control 2012, 60, 199-206.

21. Harris, E.J.; Bautista, R.C. Implications of host mortality on the economics of Fopius arisanus (Hymenoptera: Braconidae) mass rearing. Biocontrol 2001, 46, 275-287.

22. Ovruski, S.; Aluja, M.; Sivinski, J.; Wharton, R. Hymenopteran parasitoids on fruit-infesting Tephritidae (Diptera) in Latin America and the southern United States: Diversity, distribution, taxonomic status and their use in fruit fly biological control. Integr. Pest Manage. Rev. 2000, 5, $81-107$.

23. Hollingsworth, R.G. Project on Regional Management of Fruit Flies in the Pacific Status of Fruit Flies (Family Tephritidae) and Fruit Fly Research in the Solomon Islands; Solomon Islands Ministry of Agriculture and Fisheries: Honiara, Solomon Islands, 1998; p. 54.

24. Baranowski, R.; Glenn, H.; Sivinski, J. Biological control of the Caribbean fruit fly (Diptera: Tephritidae). Fla Entomol. 1993, 76, 245-251.

25. Snowball, G.J.; Lukins, R.G. Status of introduced parasites of Queensland fruit fly (Strumeta tryoni). Aust. J. Agr. Res. 1964, 15, 586-608.

26. Snowball, G.J.; Lukins, R.G. Status of introduced parasites of Queensland fruit fly (Strumeta tryoni), 1962-1965. Aust. J. Agr. Res. 1966, 17, 719-739.

27. O'Connor, B. A decade of biological control work in Fiji. Agric. J. Fiji 1960, 30, 44-54.

28. Hinckley, A.D. Fruit fly infestation and parasitization in Fiji. P. Hawaii Entomol. Soc. 1965, 19, 91-95.

29. Chong, M. Production methods for fruit fly parasites. P. Hawaii Entomol. Soc. 1962, 18, 61-63.

30. Snowball, G.V.; Wilson, F. Culture and consignment techniques used for parasites introduced against Queensland fruit fly (Strumeta tryoni Frogg.). Aust. J. Agr. Res. 1962, 13, 233-248.

31. Ramadan, M.M.; Wong, T.T.Y.; McInnis, D. Reproductive biology of Biosteres arisanus (Sonan), an egg-larval parasitoid of the oriental fruit fly. Biol. Control 1994, 4, 93-100.

32. Wang, X.G.; Bokonon-Ganta, A.H.; Ramadan, M.M.; Messing, R.H. Egg-larval Opiine parasitoids (Hym., Braconidae) of tephritid fruit fly pests do not attack the flowerhead-feeder Trupanea dubautiae (Dipt., Tephritidae). J. Appl. Entomol. 2004, 128, 716-722.

33. Harris, E.J.; Okamoto, R.Y.; Lee, C.Y.L.; Nishida, T. Suitability of Dacus dorsalis and Ceratitis capitata [Diptera, Tephritidae] as hosts of the parasitoid, Biosteres arisanus [Hymenoptera, Braconidae]. Entomophaga 1991, 36, 425-430. 
34. Bautista, R.C.; Harris, E.J.; Lawrence, P.O. Biology and rearing of the fruit fly parasitoid Biosteres arisanus: Clues to insectary propagation. Entomol. Exp. Appl. 1998, 89, 79-85.

35. Bautista, R.C.; Mochizuki, N.; Spencer, J.P.; Harris, E.J.; Ichimura, D.M. Mass-rearing of the tephritid fruit fly parasitoid Fopius arisanus (Hymenoptera: Braconidae). Biol. Control 1999, 15, 137-144.

36. Manoukis, N.; Geib, S.; Seo, D.; McKenney, M.; Vargas, R.; Jang, E. An optimized protocol for rearing Fopius arisanus, a parasitoid of Tephritid fruit flies. J. Vis. Exp. 2011, 53, e2901.

37. Vargas, R.I. Mass production of tephritid fruit flies. In World Crop Pests. Fruit Flies: Their Biology, Natural Enemies and Control; Elsevier: Amsterdam, The Netherlands, 1989; Volume 3, pp. 141-151.

38. Vargas, R.I.; Stark, J.D.; Banks, J.; Leblanc, L.; Manoukis, N.C. Spatial dynamics of two oriental fruit Fly (Diptera: Tephritidae) parasitoids, Fopius arisanus (Sonan) and Diachasmimorpha longicaudata (Ashmead) (Hymenoptera: Braconidae), in a guava orchard in Hawaii. Biocontrol 2013, sumbitted.

39. Carmichael, A.E.; Wharton, R.A.; Clarke, A.R. Opiine parasitoids (Hymenoptera: Braconidae) of tropical fruit flies (Diptera: Tephritidae) of the Australian and South Pacific region. Bull. Entomol. Res. 2005, 95, 545-569.

40. Waterhouse, D.F. Pest fruit flies in the Oceanic Pacific. In Biological Control: Pacific Prospects-Supplement 2; Australian Centre for International Agricultural Research: Canberra, Australia, 1993; Volume 2, pp. 4-47.

41. Purcell, M.F.; John, C.; Messing, R.H.; Wong, T.T.Y. Interactions between augmentatively released Diachasmimorpha longicaudata (Hymenoptera: Braconidae) and a complex of Opiine parasitoids in a commercial guava orchard. Biocontrol Sci. Technol. 1998, 8, 139-151.

42. DeBach, P.; Rosen, D. Biological Control by Natural Enemies; Cambridge University Press: Cambridge, UK, 1991.

43. Vargas, R.I.; Peck, S.L.; McQuate, G.T.; Jackson, C.G.; Stark, J.D.; Armstrong, J.W. Potential for areawide integrated management of Mediterranean fruit fly (Diptera: Tephritidae) with a Braconid parasitoid and a novel bait spray. J. Econ. Entomol. 2001, 94, 817-825.

44. Hoyt, C.P. Parasites and Predators Introduced into the Pacific Islands for the Biological Control of Insects and Other Pests; Technical Papers. South Pacific Commission: Nouméa, New Caledonia, 1957; p. 40.

45. Yokoyama, V.Y.; Rendón, P.A.; Sivinski, J. Psyttalia $c f$. concolor (Hymenoptera: Braconidae) for biological control of olive fruit fly (Diptera: Tephritidae) in California. Environ. Entomol. 2008, 37, 764-773.

46. Quimio, G.M.; Walter, G.H. Host preference and host suitability in an egg-pupal fruit fly parasitoid, Fopius arisanus (Sonan) (Hym., Braconidae). J. Appl. Entomol. 2001, 125, 135-140.

47. Nishida, T.; Haramoto, F.H. Immunity of Dacus cucurbitae to attack by certain parasites of Dacus dorsalis. J. Econ. Entomol. 1953, 46, 61-64.

48. Bautista, R.C.; Harris, E.J.; Vargas, R.I.; Jang, E.B. Parasitization of melon fly (Diptera: Tephritidae) by Fopius arisanus and Psyttalia fletcheri (Hymenoptera: Braconidae) and the effect of fruit substrates on host preference by parasitoids. Biol. Control 2004, 30, 156-164. 
49. Wharton, R.A.; Gilstrap, F.E.; Rhode, R.H.; Fischel, M.; Hart, W.G. Hymenopterous egg-pupal and larval-pupal parasitoids of Ceratitis capitata and Anastrepha spp. [Dip.: Tephritidae] in Costa Rica. Biocontrol 1981, 26, 285-290.

50. FAO. IAEA Alert notice USDA-APHIS: Elevated risk of peach fruit fly (Bactrocera zonata) from Egypt. Insect Pest Control Newsl. 2005, 65, 18.

(C) 2012 by the authors; licensee MDPI, Basel, Switzerland. This article is an open access article distributed under the terms and conditions of the Creative Commons Attribution license (http://creativecommons.org/licenses/by/3.0/). 